\title{
DE O PAIZ DO CARNAVAL PARA IL PAESE DEL CARNEVALE E LE PAYS DU CARNAVAL: OS PARATEXTOS DAS TRADUÇÕES ITALIANA E FRANCESA
}

\author{
Sandra Bagno* \\ Università degli Studi di Padova
}

\begin{abstract}
Resumo: Recordamos em 2017 os 90 anos da "Ata de incineração" que destruiu mais de 1600 livros de Jorge Amado, e entre eles 214 exemplares de $O$ Paiz do Carnaval, romance cuja primeira tradução - para o italiano, como de propósito escolhido pelo escritor - apareceria somente em 1984, com uma "nota" de Luciana Stegagno Picchio. Partindo do pressuposto que, antes da publicação da primeira edição do romance (1931), o lexicógrafo italiano Panzini já rejeitara, para a Itália, as antigas alcunhas inglesas carnival land e land of carnival; este artigo visa focalizar quais interpretações foram veiculadas, além do paratexto da tradução italiana também por aquele da tradução francesa (1990), da autoria de Alice Raillard. Tradutora que, porém, se beneficiou no seu paratexto da sua célebre entrevista Conversando com Jorge Amado (1990) que abriria novos rumos à crítica amadiana internacional.
\end{abstract}

Palavras-chave: Paratexto. Tradução. Lexicografia italiana. O Paiz do Carnaval.

\footnotetext{
* Possui graduação e mestrado em Lettere e Filosofia pela Universitàdegli Studi di Padova, Itália. Atualmente é professsora associada do Dipartimento di Studi Linguistici e Letterari (DiSLL) da Università degli Studi di Padova. Pádua, Pádua, Itália. E-mail: sandra.bagno@gmail.com
} 


\title{
FROM O PAIZ DO CARNAVAL TO IL PAESE DEL CARNEVALE AND LE PAYS DU CARNAVAL: THE PARATEXTS OF THE ITALIAN AND FRENCH TRANSLATIONS
}

\begin{abstract}
The year 2017 makes us remember the 90 years of the "Ata de Incineração" (Burning Act) which destroyed more than 1600 books of Jorge Amado, and among them 214 copies of $O$ Paiz do Carnaval, a novel whose first translation, which was made into the Italian language, according to the desire of Amado himself, appeared only in 1984, with a "note" by Luciana Stegagno Picchio. Presupposing that, before the publication of the first edition of the novel (1931), the Italian lexicographer Panzini had already rejected, for Italy, the old English nicknames carnival land and land of carnival; this article wants to highlight which interpretations were vehicled, both by the paratext of the Italian translation and by the one of the French translation (1990), written by Alice Raillard. A translator who, however, took advantage of her famous interview Conversando com Jorge Amado, 1990 (Talking with Jorge Amado), which would open new paths to international criticism.
\end{abstract}

Keywords: Paratext. Traduction. Italian lexicography. O Paiz do Carnaval.

\section{As duas primeiras traduções de $O$ Paiz do Carnaval: para o italiano e para o francês}

\subsection{A edição italiana: "única exceção"}

Este 2017 traz à nossa memória o nonagésimo de um dramático evento que, no ano em que Getúlio Vargas instalava o Estado Novo, foi anunciado ao Brasil pelo jornal Estado da Bahia (17/12/1937) com um artigo cujo título ameaçador fora "Ata de incineração". Como se depreende dos números pontualmente transcritos, Jorge Amado foi o escritor mais atingido pela providência. De fato, foram-se literalmente em fumaça, pois "julgados como simpatizantes do credo comunista", além de 1600 exemplares de seus romances. E enquanto as autoridades procediam ao macabro ritual, 
Jorge Amado encontrava-se preso na cadeia. Como o próprio autor lembra na entrevista Conversando com Jorge Amado, publicada em 1990 por Alice Raillard, autorizada estudiosa francesa da obra amadiana (RAILLARD, 1990, p. 100 e segs.).

Objetivo do nosso artigo é procurar entender, à luz das teorias de Gérard Genette (GENETTE, 2009), como a complexa história de $O$ Paiz do Carnaval (AMADO, 1931, p. 3) ${ }^{1}$ - incluído o estigma da fogueira da censura varguista - foi veiculada a nível internacional. Principalmente a partir da primeira tradução do romance, Il Paese del Carnevale, de Elena Grechi e publicada na Itália em 1984 "con una nota di Luciana Stegagno Picchio". (AMADO, 1984 , p. 3) O nosso interesse pelo romance amadiano de estreia se deve a um dado objetivo. Enquanto os outros romances, eles também entregues às chamas em 1937, conseguiriam posteriormente uma grande projeção, além de que nacional também internacional, graças às respectivas traduções em várias línguas (FRAGA, 2009, p. 163 e segs.), com $O$ Paiz do Carnaval não se daria igual processo. O romance deveria esperar por mais de 50 anos a sua primeira tradução.

A especificidade da tradução italiana Il Paese del Carnevale, no mapa da difusão internacional do romance, foi salientada pelo próprio Amado na supracitada entrevista:

É verdade que até há pouco tempo eu nunca consenti que o livro fosse traduzido. Em país algum. Finalmente aceitei que ele fosse lançado na Itália, onde já me pediram há muito tempo, mas foi Luciana Stegagno Picchio quem conseguiu me convencer: uma ótima amiga, que além disso é uma das maiores especialistas em literatura brasileira - é a autora de História da Literatura Brasileira, que, dizem, é a melhor que existe. Talvez. E ela conhece muito bem o meu trabalho, sobre o qual escreveu muito. Prefaciou a edição italiana para poder situar o livro. Mas, até aqui, foi a única

${ }^{1}$ As citações tiradas deste como de todos os outros volumes serão feitas no respeito das ortografias orginárias.

Cad. Trad., Florianópolis, v. 37, $\mathrm{n}^{0}$ 2, p. 17-39, mai-ago 2017 
exceção. A edição francesa será a segunda. (RAILLARD, 1990, p. 45 )

A edição francesa a que alude Amado, Le Pays do Carnaval, seria publicada também em 1990 e, como a entrevista, seria da autoria de Alice Raillard (AMADO, 1990).

\subsection{O paratexto da tradução francesa: um "Advertissement"}

Ora, na esteira de quanto afirmado pelo escritor na entrevista, também Raillard, apresentando brevemente Le Pays do Carnaval, "cette "œuvre de jeunesse", écrite à dix-huit ans", julga prioritário salientar, no seu "Advertissement", o papel de Stegagno Picchio para que se chegasse à tradução italiana:

Publié au Brésil en 1931, Le Pays du Carnaval est le premier roman de Jorge Amado. Jusqu'à une date récente, cette "œuvre de jeunesse", écrite à dix-huit ans, n'avait pu être lue qu'en portugais selon le vœu exprès de son auteur. Ce n'est qu'en 1984, et sur les instances du Pr Luciana Stegagno Picchio, que Jorge Amado accepta, à titre exceptionnel, que ce livre paraisse en Italie, dans une édition spéciale réalisée à l'occasion de son anniversaire. ${ }^{2} \mathrm{~A}$ la suite de quoi il a bien voulu m'autoriser à traduire à mom tour ce livre ancien. Qu'il en soit remercié. A.R.(AMADO, 1990, p. 9)

Porém, observando bem, entre a primeira e a segunda tradução irão transcorrer cerca de mais seis anos. Por qual razão, então, Amado hesitaria novamente antes de autorizar a segunda tradução? E sobretudo, além dos laços de profunda amizade estreitados com

${ }^{2}$ Nossos os grifos. 
Stegagno Picchio, porque ele privilegiaria o contexto italiano? E ainda: passados seis anos após a publicação de Il Paese del Carnevale, seria uma simples coincidência a contextual publicação de Conversando com Jorge Amado e Le Pays du Carnaval?

Para procurar umas respostas a essas perguntas voltemos àquele 1930, ano crucial na história do Brasil do século XX, cuja crônica se reflete, come é sabido, no romance amadiano. E recomeçemos de uma específica questão: a de seu título.

De fato, as pesquisas por nós realizadas para compreender, em primeiro lugar, como Amado chegaria a um título tão provocativo (BAGNO, 2014, p. 17-26), levam a supor que a sua escolha da língua italiana para a primeira tradução não se deveria somente à ação persuasiva de Stegagno Picchio. Mas deve antes ser relacionada ao contexto internacional, a que o escritor emblematicamente alude desde as primeiras páginas do romance: pois estas começam com a chegada ao Rio de Janeiro na época do Carnaval, e após uma longa permanência na França onde completara sua formação, do herdeiro de uma fazenda de cacau na Bahia, Paulo Rigger. Um brasileiro, portanto, mas que logo se revela sui generis pela incapacidade de se adequar, depois de tanto tempo na Europa, ao seu próprio país.

\section{Do inglês ao português: de Carnival-nation e land of carnival a $O$ Paiz do Carnaval}

Se em vez de ler o romance amadiano como uma das testemunhas do debate político-cultural brasileiro na virada de ' 20 a ' 30 , o contextualizarmos no coevo cenário especificamente linguistico internacional, um elemento ressalta entre outros. E este impõe que o título do romance seja relacionado a uma antiga alcunha e tradicionalmente usada contra a Itália, cuja ocerrência seria reconhecível no contexto linguístico-cultural anglosaxônico bem antes não somente da publicação do romance amadiano, mas também da eclosão do movimento modernista. Esse elemento depreende-se claramente das atestações do lexicógrafo Alfredo Panzini (1863 - 
1939), autor do Dizionario Moderno: uma obra especial no seu gênero, e de grande importância na tradição cultural italiana. (PANZINI, 1950) E obra que, vale a pena lembrar, certamente era do conhecimento de uma filóloga como Stegagno Picchio.

Uma das peculiaridades do Dizionario Moderno é a riqueza de verbetes registrando, sem qualquer preconceito, palavras e locuções estrangeiras, mesmo num clima em que se afirmariam cada vez mais tendências nacionalistas. Entre as palavras e locuções estrangeiras, Panzini documenta, com definições que iria parcialmente modificar nas posteriores edições do Dizionario Moderno, duas locuções em inglês: carnival-nation e land of carnival. E mais exatamente, na edição de 1905 aparece somente a primeira locução:

Carnival-nation: epiteto sprezzantemente ingiurioso già dato dagli Inglesi all'Italia: nazione carnascialesca. L'indolenza, l'indifferenza e la naturale fertilità del nostro popolo, specie delle terre meridionali, spiegano la parola. Mutati i tempi e pur migliorate le cose, permane tuttavia l'abitudine festaiuola per ogni occasione, lieta o triste che sia [...] (PANZINI, 1905, p. 80-81)

Já numa posterior edição o lexicógrafo modificaria a definição nos seguintes termos:

Carnival nation o land of carnival [...]: epiteto già dato dagli Inglesi all'Italia: nazione festaiuola e celebre un tempo per i suoi carnevali (Roma, Milano, Venezia). Ora le cose sono mutate! (PANZINI, 1950, p. 114)

Portanto, segundo testemunha Panzini, antes de 1905, há tempo a Itália teria sido alvo de desprezo, no contexto linguístico-cultural anglosaxônico, sendo definida carnival nation ou land of carnival. $\mathrm{E}$ as definições de Panzini colocam claramente a questão de como 
aquelas duas alcunhas (ou duas versões de uma mesma alcunha) carregassem implicações políticas («Ora le cose sno cambiate!”), que é verossímil reconduzir à profunda fratura entre a Inglaterra scismática e a igreja católica romana.

Este dado, já por si importante para quem colocar a questão de como aquelas alcunhas teriam chegado à língua portuguesa do Brasil - e portanto a questão de qual a origem do título do romance amadiano -; pois bem, este dado se torna ainda mais importante também de outro ponto de vista: Panzini se recusa em dissimular, no seu Dizionario Moderno, duas alcunhas mesmo que estrangeiras, e mesmo que evidentemente incorretas do ponto de vista político e da autoestima nacional. ${ }^{3}$ Pelo contrário, justamente por constarem, como verbetes, num dicionário, as definições do Panzini se tornariam uma espécie de antídoto, capaz de implicitamente anular os originários cunhos negativos.

À luz de uma óbvia circulação internacional das duas alcunhas, visto o papel já na época do inglês - circulação que com certeza não pode ter excluído o Brasil do começo do século XX - torna-se óbvio hipotizar que possam ter acontecido pelo menos três circunstâncias. As duas primeiras concernentes o próprio jovem escritor e a serem contextualizadas em 1930, quando ainda existia no Brasil uma liberdade de expressão artística. E momento em que Amado toma posição, sem meios termos, no público debate com $O$ Paiz do Carnaval. Já a terceira circunstância deve ser hipotizada no clima político brasileiro de poucos anos posteriores: o da ditadura varguista baseada, além do mais, numa censura que se tornara especialmente feroz justamente em 1937. Como a fogueira encenada em Salvador - um fac-símile das fogueiras nazistas - tristemente demonstraria.

Mais especificamente, em primeiro lugar: quando em 1930 Amado escreve seu romance e faz com que a alcunha "o Paiz do Carnaval" saia da boca de um fazendeiro que, mesmo se benefician-

\footnotetext{
${ }^{3}$ Para a tendência da lexicografia italiana a não dissimular palavras e locuções politicamente incorretas v. BAGNO, Sandra. Lessicografia e identità brasiliana: dov'è "A nossa Vendéia"? Da Alcácer-Quibir a Vendéia: voci del "tempo di lunga durata" della "civiltà nazionale" brasiliana. Padova: CLEUP, 2006.
} 
do de um status social que o Brasil lhe garantia, de fato despreza a sua identidade de brasileiro, como demonstra o uso, repetidas vezes, daquela alcunha contra o seu país; então, é óbvio supor, como dizíamos, que Amado bem conhecesse pelo menos uma das duas alcunhas (land of carnival), por ter sido veiculada pela língua inglesa.

Em segundo lugar, posto que a primeira edição do Dizionario Moderno é de 1905, não se pode excluir a eventualidade de que Amado soubesse que uma (ou ambas) as alcunhas tinham sido usadas pelos Ingleses contra uma Itália 'culpada' de ter, na sua complexa história política de vária maneira interligada ao catolicismo romano, também uma célebre tradição carnavalesca, cujas raízes recuavam além da antiguidade clássica.

Em terceiro lugar, menos ainda podemos excluir a eventualidade de que estivessem bem cientes das significações daquelas duas alcunhas os censores do Estado Novo. Que teriam reagido com violência contra Amado ainda mais porque, se em '37 o escritor estava obviamente 'manchado' também pela comprovada militância política “comunista”, quando adolescente, já tivera a impudência de adotar uma das mais infamantes alcunhas para uma nacionalidade - $O$ Paiz do Carnaval - e até como título e fio vermelho de seu romance. Portanto, é lógico supor que aqueles censores tenham reagido principalmente ao ler o trecho do romance em que, além que contra seu país, Paulo Rigger recorre àquela alcunha xingando o "Presidente ou Ditador": ou seja, aquele Getúlio Vargas que, em 1930, acabara de se afirmar no palco político nacional; mas que em 1937 já tinha consolidado uma ditadura fundada também sobre lógicas nacionalistas autocelebrativas. E que com certeza não suportava, além dos "simpatizantes do credo comunista", qualquer forma de ofensa, ou simplesmente de crítica, que pudesse atingir a imagem do país, tanto na percepção do povo brasileiro como naquela da comunidade internacional. Por ambas estas razões $O$ Paiz do Carnaval - independendo de qual personagem recorre no romance àquela alcunha e porque - poderia ter sido interpretado pela inquisição varguista como ainda mais subversivo. 
Aguardando os resultados de mais aprofundadas pesquisas sobre estes aspectos da história do romance, de qualquer maneira as definições do Panzini demostram que $O$ Paiz do Carnaval como título e leitmotiv estabelece, pelo menos em termos histórico-cultural e linguístico, uma relação direta entre a tradição italiana, católica e caracterizada pelo seu afamado carnevale, e aquela brasileira. Isto é, de um país também católico e que, nas primeiras décadas do século XX, já se tornara uma referência pelo seu Carnaval cada vez mais original. Como iam confirmando os crescentes fluxos de turistas a que o próprio Amado se refere desde as primeiras páginas do romance.

\section{A "nota" de Stegano Picchio: "Il Paese del Carnevale: un topos di Jorge Amado"}

O paratexto da tradução italiana (que antecede de seis anos, como sabemos, tanto a entrevista de Raillard como a tradução Le Pays du Carnaval) é de outra extensão se comparada com o "Adevertissement" da edição francesa. Observemos, então, como Stegagno Picchio "Prefaciou a edição italiana para poder", segundo as palavras de Amado, "situar o livro". E procuremos entender se ela recorreu, de maneira direta ou indireta, ao legado do seu compatriota, o lexicógrafo Panzini: que, com as suas definições daquelas alcunhas, oferece preciosas chaves de leitura para interpretar o inteiro romance. Pois, elas levam a supor que Amado possa ter percebido o humus cultural italiano como o mais adequado e do qual partir, principalmente se com uma tradução devidamente acompanhada por um "prefácio" (na realidade, uma "nota”), para uma posterior maior difusão do romance.

\subsection{Um "Carnevale "di segno negativo",}

A "nota", cujo título "Il Paese del Carnevale: un topos di Jorge Amado" logo focaliza a importância do assunto Carnaval na inteira obra amadiana, começa: 
Jorge Amado alla ribalta di ogni paese del mondo, tradotto, illustrato, massificato. I suoi ventotto "romanzi" - se vi si includono le biografie, di uomini e di città, che sono storie reinventate nel reale - riversati in film, telenovelas, musicals. I suoi pesonaggi assunti ad insigne di bar, ristoranti, scuole di samba, dentro e fuori del Brasile. Un Brasile che si riconosce e a sua volta si rivela e autopresenta nel Carnevale, festa bifronte nuova e antica, esplosione di una gente mista, capace di recuperare, nello scenario barocco del Tropico, l'ingenuità catartica di nuovi mondi, Africa, Orienti, Americhe. Jorge Amado cronista e interprete autorizzato del Carnevale brasiliano. (AMADO, 1984, p. 131)

Salientada toda a importância internacional, graças às muitas traduções, atingida ao longo do século XX pelos outros romances amadianos, Stegagno Picchio é a primeira (cronologicamente) a recordar a exceção representada a este respeito pelo romance de estreia, e, por conseguinte, o papel da tradução Il Paese del Carnevale. Mas além desta há, segundo a estudiosa italiana, uma outra "diversità" que caracteriza o romace, a de apresentar um "Carnevale di segno negativo":

La sequenza è corretta e non manca di giustificazione. I pubblici non brasiliani che da anni frequentano sia pure in traduzione la foresta di simboli che emerge dalla prosa gonfia, succolenta, di Amado, avvertiranno tuttavia immediatamente come il Carnevale di segno negativo di questo mai tradotto ed esportato libro d'esordio sia diverso nel suo significato e nella sua messinscena dai Carnevali terapeutici che percorrono in sequenze da Orfeo negro i successivi best-sellers, da "Jubiabá" a "Dona Flor" e a "Tieta". (Ibidem)

Ora, ao impostar a sua interpretação do romance em função do leitor italiano (que por certo há tempo, em 1984, não estava mais 
preocupado de que a Itália tivera sido definida pelos Ingleses carnival land e/ou land of carnival), Stegagno Picchio, contrapondo um "Carnevale" tout court "di segno negativo" (em Il Paese del Carnevale) àqueles "terapeutici" (nos "successivi best sellers"), está tirando proveito, de qualquer maneira, do legado panziniano? Vejamos.

No trecho seguinte, a estudiosa passa a uns dados biográficos do autor para explicar como ele fora precoce na sua atuação nos meios artísticos e intelectuais da época (AMADO, 1984, p.131-132). ${ }^{4}$ Mas retornando logo após ao romance de estreia, ela volta sobre a questão da recusa, longamente mantida por Amado, de qualquer tradução:

Con la sua esile prosa modernista, tessuta di periodi brevi, di frasi nominali, tese a cogliere in ironiche, aquarellate istantanee, una realtà nazionale vista dal di fuori con gli occhi e lo straniamento del reduce (l'azzurro del cielo, il verde del mare, il giallo-verde del gigante Brasile), il "Paese del Carnevale" resta, solo, sul ciglio. Con tutte le sue valenze esistenziali, estetiche, letterarie, apparentemente non saturate. Il che spiega e in un certo senso giustifica il lungo rifiuto opposto da Jorge Amado agli editori di ogni paese perché

\footnotetext{
4 "Nel 1931 Jorge Amado aveva 19 anni. Figlio di un piatatore di cacao del sud della Bahia, si era affacciato prestissimo al mondo delle lettere, cronista, critico, narratore. In società con due giovani amici, Dias Costa ed Edison Carneiro, aveva pubblicato in sordina nel 1929, prima a puntate sul 'Jornal' di Bahia, sotto lo pseudonimo di I. Karl, e poi in volume, un romanzino o romanzaccio, 'Lenita', espunto in seguito dalle sue opere complete, dove non figura neppure l'altro volume collettivo, 'Brandão entre o mar e o amor', che nel 1941 giustapporrà il nome di Amado a quello di altri narratori amici e illustri: José Lins do Rego, Graciliano Ramos, Aníbal Machado e Rachel de Queiroz. In questo senso, il 'Paese del Carnvale', scritto o almeno concluso a Rio, nel dicembre del 1930 e ivi pubblicato, in una adizioncina di mille esemplari, nel settembre 1931, è senza dubbio il libro d'esordio. [...] Scritto in prima persona, in una assunzione-identificazione autobiografica di eventi e responsabilità che i successivi romanzi solo continueranno a realizzare, Cacao segna davvero l'inizio di quella prima fase della narrativa di Jorge Amado che la critica ha classificato da sempre come impegnata, sociale, sociopolitica, se si vuole: contrapponendola, a volte con troppo rigido manicheismo, alla seconda fase, poeticamente disimpegnata, aperta nel 1958 da Gabriella, garofano e Cannella." (AMADO, 1984, p. 131-132)
} 
anche quest'opera prima si allineasse negli scaffali delle traduzioni a completare l'immagine di un narratore tanto ubiquamente popolare. Temeva forse Amado che i suoi lettori, per cui spesso la successione temporale delle opere di uno scrittore si istituisce secondo la progressione delle versioni, non sapessero fare il salto all'indietro indispensabile per la comprensione del libro. (AMADO, 1984, p. 132)

A hipótese de que os leitores italianos de Il Paese del Carnevale "non sapessero fare il salto all'indietro indispensabile per la comprensione" (de um livro cujo título, pelo contrário, dada a tradição cultural italiana, nenhuma dificuldade oferece a este respeito); pois bem, esta hipótese fecha de vez a uma interpretação baseada no legado panziniano. Qual será, então, a linha crítica escolhida pela estudiosa? Voltemos à "nota".

\subsection{Il Paese del Carnevale na moldura das articulações do Modernismo}

O devido enquadramento histórico da "importanza" do romance de estreia impõe citar, por um lado, o Modernismo, e, por outro, Getúlio Vargas:

Ma il romanzo è importante. Non solo come verifica di una vocazione letteraria di precocissime epifanie. Non solo come tessera marcata di una collettiva avventura modernista che proprio in quegli anni darà il giro di boa della risemantizzazione e dell'assunzione di impegno nazionalista. Non solo come documento di un Brasile 1930 all'indomani di un rivolgimento politico che di lì innanzi si identificherà col nome e la figura, passionale, enigmática, contraddittoria, di Getúlio Vargas. Ma come testo letterario. Un testo che si legge in un fiato, materiato com'è di dialoghi, aforismi, notazioni ironiche. Con, nello sfondo, il modelo insuperato e inarrivabile di Machado de Assis e, in primo piano, il 
gioco cubista della prosa in pillole, dell'immaginazione senza fili, della sintassi sintetica e folgorante di un Oswald de Andrade, della prosa telegrafica, simultaneista, di un Alcantara Machado, cronista dei quartieri italiani di una São Paulo di emigrazione. (AMADO, 1984, p. 133)

\title{
Após ter explicado as fases do Modernismo, assim como em ge- ral descritas pelos manuais, ${ }_{5}^{5}$ Stegagno Picchio retorna ao romance amadiano:
}

\begin{abstract}
Opera di un ragazzo di diciannove anni, "Il Paese del Carnevale" di Jorge Amado sembra riassumere, annunciare (e preludere) tutto questo. Anche, perché nella ricostruzione di un contesto culturale come quello in cui si colloca la vicenda, introduce le nozioni di generazione e di gruppo che tanta importanza assumeranno nel contemporaneo affresco dell'intelligenza brasiliana. Come sempre nell'opera di un Amado rapsodo (nel senso mitico e apologizzante del termine) di una saga nazionale, ma insieme fissatore in storie ora tenere ed ora ironiche, di precise esperienze personali, alla base c'è la biografia: la parabola esistenziale di un uomo che nel 1930 era uno "scrittorello apprendista",
\end{abstract}

\footnotetext{
5 "Nel 1930 il Modernismo che nel 1922 aveva lanciato sempre da São Paulo, in nome di una tardiva, ma vitalíssima avanguardia nazionale, il grido antropofagico del rifiuto dell'Europa, sentiva esaurita la propria iniziale carica rivoluzionaria. Finito il Brasile di ironici ed inesistenti indios neoromantici di penne posticce ad incarnare cattivi selvaggi da operetta. La realtà era il negro, la siccità del Nordest, il personaggio emergente del 'cavaleire della speranza' Antonio Prestes, le grandi idee che come sempre venivano dall'Europa, il comunismo, il fascismo. Non era più tempo di fughe nella Pasargada mitica e possibilistica di un Manuel Bandeira, da stilizzati simboli europei, Pierrot e Arlecchino; di futurismi, sapidi di ottimismo e di trionfalistica fiducia nell'uomo; di disimpegnate avventure panestetiche nel linguaggio e nella storia dell'uomo. La borsa di Wall Street ha dato il segnale. Ciascuno torna nella sua tana a rimuginare, ravveduto e impegnato, la propria problematica sociale e nazionale. Nasce il romanzo radicale del Nordest. Comincia quella che la letteratura dei manuali definirà come secondo Medernismo, o Modernismo del Trenta, contrapposto al Modernismo paulista del Venti, e destinato a durare fino alla fine della seconda guerra mondiale, quando, com la cosiddetta Generazione del '45, un nuovo disimpegno, formale ed estetizzante, si reinstallerà nella repubblica delle lettere brasiliane." (AMADO, 1984, p. 133)
} 
membro di una fantomatica Accademia dei Ribelli, impegnato per la maggior parte della giornata in discussioni di caffé con gli amici (le donne, le grandi idee, la scelta della vita). Un vitellonismo di provincia in cui peraltro già si affacciano i grandi ideali e le grandi disillusioni del nostro secolo.(AMADO, 1984, p. 133-134)

Entre os aspectos a serem ressaltados, com razão a estudiosa italiana cita o da influência, "nell'opera di un Amado rapsodo", da sua "biografia" e da sua "parabola esistenziale": mas para chegar a quais conclusões?

\section{Paulo Rigger, "personaggio negativo del protagonista"}

Adentrando-se na interpretação do romance, depois de ter definido "il Carnevale 'di segno negativo"”, Stegagno Picchio afirma que o que caracteriza o protagonista Paulo Rigger é sua "connotazione del personaggio negativo":

Nel Brasile come ieri, come oggi, come sempre, sull'"orlo dell'abisso" ("lascialo cadere, lascialo cadere, divertentissimo il Brasile in fondo all'abisso", commentano con cinica incoscienza i vitelloni), torna dall'Europa il giovane Paulo Rigger, figlio di ricchi piantatori di caffé [sic!] che la prassi della classe dominante brasiliana aveva sette anni prima inviato in trasferta di acculturamento a Parigi. Torna disincantato e blasé (la parola è del gergo vitellonesco), parigino negli abiti e negli atteggiamenti, diffidente di una patria che la visione europea, di un Blaise Cendrars, lo ha abituato a "kodakare" come il Paese del Carnevale. Dove la connotazione negativa della formula, applicata in apertura alla piccola società altoborghese a categoriale, come una medievale danza della morte (il senatore, il "fazendeiro", il vescovo, la signora, l'intellettuale di provincia) che riempie il ponte del transatlantico, diviene anche connotazione del personaggio negativo del 
protagonista, incapace di scegliere o di accettare, di volere o semplicemente di essere brasiliano. (AMADO, 1984, p. 134)

Na esteira do binômio "Carnevale di segno negativo" / Paulo Rigger "personaggio negativo", Stegagno Picchio detem-se para observar os vários momentos em que "la connotazione negativa della formula" (il Paese del Carnevale) retorna ao longo dos capítulos, "[...] ad intervalli, come a pausare, con un ritornello riflessivo e significante, la banale avventura patria del figlio dei fazendeiros" (Idem, Ibidem). E de fato, aquela "formula" logo reaparece:

\begin{abstract}
«Lontano, laggiù, il Paese del Carnevale", nel momento in cui la nave avvista terra e il reduce, tornato fanciullo sotto la patina della cultura altra, antivede e subito rifiuta un mitico paese dei balocchi anteriore al peccato originale, ma banalizzato, deresponsabilizzato, nella proposta del baloccosesso. Il Brasile "paese dei grandi uomini e del Carnevale", nel repentino tuffo del brasiliano venuto di lontano entro l'euforia collettiva del Regno della Carne. Dove già, fra le virtuose figlie di moralisti bianchi sfrenate anch'esse nel rito collettivo in sabato di Carnevale, si aprono finestre di sensualità le mulattine color cannella che sambano innocenti e diaboliche per le strade di Rio e preludono alle future Gabriella, Teresa Batista, Tieta dell'ultima stagione "solare" del narratore. (AMADO, 1984, p. 134-135)
\end{abstract}

E a mesma (ou quase a mesma) "formula negativa" aparece novamente em outros importantes momentos.

\title{
4.1 A identificação "Paulo Rigger/Amado" em um "paese da operetta (il Carnevale sempre)"
}

Ora, Stegagno Picchio passa, sem hesitação alguma, a identificar Paulo Rigger, com toda sua negatividade, com o adolescente escritor Jorge Amado: 
"Ragazza mia, questo è il Paese del Carnevale": è la sconsolata rivelazione della propria estranietà di inadeguatezza da parte di un Paulo Rigger/Amado sommerso dalla bolsa retorica degli oratori nazionali. Quando non sono le notizie serioese dei quotidiani: il popolo scontento perché il Governo rifiuta ai club carnevaleschi la "sovvenzione di rito" ("Paese del Carnevale, paese del Carnevale. Se io fossi Presidente o Dittatore, decreterei un Carnevale di 365 giorni. Mi adorerebbero"). Sino al disilluso finale, in cui un Paulo Rigger che non ha saputo serenamente accettare la rivelazione di perduta verginità della promessa sposa, di un Paulo Rigger che solo si è sentito brasiliano due volte nella vita, quando ha "sambato" per le strade di una Rio smemorata nel Carnevale, e quando ha picchiato di sana ragione, secondo il gusto e il rito patrio, dopo il di lei tradimento, la piccola prostituta francese con cui vive, rifiuta patria e nazionalità per fuggire dal Brasile impazzito nella Domenica di Carnevale. (AMADO, 1984, p. 135)

Portanto, segundo Stegagno Picchio "un Paulo Rigger/Amado" teria usado aquele "ritornello" para chegar a justificar, enfim, todo seu desgosto pela sua "patria e nazionalità", "per fuggire dal Brasile impazzito nella Domenica di Carnevale".

Mas esta interpretação levanta umas questões. Como Amado não podia imaginar, quando estava com 18 anos, que teria que fugir do Brasil (e quando fugiria, com certeza não seria por desprezar o seu povo, pois estava fugindo dos seus algozes); então, é verosímil que ele tenha se reconhecido, em 1984, numa interpretação baseada na identificação Paulo Rigger/Jorge Amado?

Antes de procurarmos responder a esta pergunta e às outras anteriormente colocadas, vamos à última parte da "nota", em que Stegagno Picchio, com razão, salienta o rápido sucesso conseguido por $O$ Paiz do Carnaval, tanto pelo lado da crítica como pelo do público. Pois, do jornal 
[...] "A Razão", Otávio de Faria lo saluta come un grande romanzo, un passo avanti e un mutamento di direzione nella narrativa nazionale, anche se, come egli dice, maculato da Frasi scandalose, espressione di una generazione rivoltata, alla ricerca di un alibi e di un riscatto e incapace di trovarlo fuori della boemia notturna dell'avventura da strapazzo, del convivio con gli amici sterilmente cerebrali, con le opulente ancorché squallide prostitute della notte baiana. Dal canto suo Schmidt lo presenta come il geniale prodotto di una rivolta giovanile che lui, singolarmente, è già riuscito a superare. Una triste testimonianza di una gioventù priva di una carta nautica che la guidi al Porto. (AMADO, 1984, p. 135)

Prosseguindo pelo caminho escolhido, Stegagno Picchio chega a afirmar que Amado fez "Un foto-documento di ciò che siamo oggi: piccoli intellettuali in un paese da operetta (il Carnevale sempre), che fugge da se stesso e dalla Soluzione, se soluzione esiste fuori dell'alibi trascendentale." (Idem, Ibidem) Mas será que o jovem Amado pensou no seu País como um "paese da operetta"?

Quanto à novidade do estilo, a estudiosa salienta que o escritor usa umas específicas técnicas:

Sono gli aforismi, le affermazioni, come quelle che un Jorge Amado giovanilmente cinico o ancor esitante pone in bocca a un Paulo Rigger trasparentemente autobiografico (anche se nella finzione leggermente invecchiato), ad attrarre l'interesse e la censura dei benpensanti. Come quando, con dottorale sicumera il personaggio Ricardo Brás, in un indicativo accostamento delle ideologie politiche a quelle di lupanare, predica agli amici: "Né comunismo, né fascismo". O come quando lo stesso Jorge Amado, in una autopresentazione poi soppressa nelle edizioni successive, quando già la scelta della causa sarà effettuata, anche con sacrifício della vita indviduale, dichiara lucidamente: "Non 
posso battermi per una causa. Io sono ancora uno che cerca”. (AMADO, 1984, p. 135-136) ${ }^{6}$

Nesta densa descrição de uma trajetória artística amadiana logo do começo complexa - tanto que, segundo Stegagno Picchio, se refleteria plenamente num "Paulo Rigger trasparentemente autobiografico" - entre as muitas referências citadas não poderia faltar Retrato do Brasil de Paulo Prado:

\begin{abstract}
Pochi, nel Trenta, sentono il valore trasfigurante e insieme ironicamente documentario di un linguaggio "quotidiano", materiato di echi della banalità conversatoria del brasiliano medio (l'enfasi "Ufanista", apologetica della bellezza di un paesaggio reclamizzato come "il più bello del mondo", il topos attinto a un Paulo Prado, autore nel 1929 di un melanconico "Ritratto del Brasile", del brasiliano indolente, in una terra felice vive un popolo triste). (AMADO, 1984, p. 136)
\end{abstract}

\title{
Assim como não poderia faltar uma pontual referência ao triste evento cujo nonagésimo recordamos neste 2017:
}

\footnotetext{
${ }^{6} \mathrm{O}$ panorama das reações da crítica é apresentado por Stegagno Picchio nos seguintes termos: "Critica di contenuti, di ideologie, di buone intenzioni. Pochi fanno attenzione a quanto ora particolarmente ci interessa: al significante, a quella prosa tenue, intenzionalmente modernista ("il sole è stato il primo cubista del mondo", è aforisma di apertura), interpretata al rovescio, ad esempio da un critico-narratore quale Marques Rebelo nel 1932, come "massimo disprezzo per la letteratura", dove letteratura stava per retorica al modo nazionale, ma dove pareva che insieme si dimenticasse come anche l'avanguardia soglia obbedire ad una sua precisa retorica: la retorica dell'antiretorica. Pochi fra i critici del Trenta (e anche di oggi) si soffermano sul gioco inusuale, ma molto modernista, molto Oswald de Andrade, della citazione (il ritornello crudele e sambato del "dá nela, dá nela”, "picchiala, picchiala", antifemminista), dell'inserto poetico (l'Ode alla mulatta sconosciuta), della lettera all'amico Ricardo Brás citata ipsis verbis, come nel discorso orale, solo nel passo pertinente al racconto, del manifesto a caratteri cubitali annunziatore del comizio antirivoluzionario, del corsivo introdotto a mettere l'accento, a singolarizzare nel loro significato "di classe", parole e frasi captate in regime di oralità (per fortuna noi siamo sfortunati, bisogna trovare un senso, un fine, alla vita"). Tutti artifizi che ritroveremo, ma come che tradotti al popolare, al rurale, al cordel", nel futuro Jorge Amado dell'affabulazione epica." (Idem, Ibidem)
} 
E non è sicuramente per caso, o solo per essere opera di un Jorge Amado poi decisamente rivoluzionario e impegnato in una precisa direzione politica, che, in pieno riflusso antirivoluzionario, il 19 novrembre 1937, nell'antica piazza che fronteggia la Scuola della Bahia, 214 esemplari del "País do Carnaval" vennero publicamente bruciati insieme ad 89 esemplari di "Cacau", a 93 esemplari di "Suor", a 267 esemplari di "Jubiabá", a 223 esemplari di "Mar morto" e a 808 esemplari di "Capitães de areia": il tutto per ordine del Comando della Sesta Regione Militare, a dimostrazione che l'Inquisizione, nelle aree di suo maggior prestigio, non ha mai cessato di esistere. (AMADO, 1984, p. 136-137)

\subsection{Jorge Amado "riduttivo eteronimo" di Paulo Rigger"}

Mas, retornando àquele 1930, Stegagno Picchio não esquece de sublinhar novamente o grande sucesso obtido por um escritor de fato adolescente:

Nel 1930, tuttavia, questi tempi sono ancora di là da venire: il pubblico si diverte e il libro dell'adolescente Jorge Amado ha una pronta ristampa, di duemila esemplari, già nel luglio del 1932, dando inizio all'avventura nazionale di un Amado omologo tropicale del Balzac della Commedia umana e come lui disposto a riproporre i propri personaggi in diverse avventure esistenziali e in diversi libri. Come se ogni volta li catturasse dalla realtà, anziché dalla finzione: ritagliati nel tessuto della vita, o, se si vuole, della storia, e come tali proprietà di ciascuno. (AMADO, 1984, p. 137)

Ao aproximar-se da conclusão, a estudiosa reafirma a ideia sobre a qual fundamenta toda sua apresentação, e desta vez até evocando uma categoria interpretativa ligada à tradição crítica pessoana, a de um Jorge Amado "riduttivo eteronimo" de Paulo Rigger": 
Certo, anche se oggi i suoi critici si ammantano di sapienza europea, il Brasile ha inventato il Carnevale prima di Bachtin. Perché il Brasile è il paese del Carnevale. Solo che il Carnevale può avere molti e diversi significati in Brasile e per il Brasile. Al di là del rifiuto di inadeguatezza che il suo riduttivo eteronimo ${ }^{7}$ Paulo Rigger compie in limine al suo frustrato tentativo di recuperare una patria e un'identità nazionale, Jorge Amado tornerà ad immergesi nel Carnevale patrio. $\mathrm{Ci}$ tornerà dopo aver attraversato in finzione le distese infuocate del cacao di Iheus, le selve contese fra colonnelli di epopea e piccoli avventurieri senza scrupolo, e dopo aver macerato in prima persona, negli anni dell'esilio politico, la nostalgia di una terra promessa di socialità primitiva e avveniristica. Il Carnevale dell'interazione razziale, della festa di una razza che si riconosce nel molteplice e nell'impuro, nel mescolato. Anche se il carnevale di questo "Paese del Carnevale" rimarrà per sempre al di qua della festa, col suo sdegnoso rifiuto, con la sua intellettualistica lucida condanna. (Ibidem)

Estas as principais ideias da "nota" assinada por Stegagno Picchio em "Santa Barbara, Ca., 1 maggio 1984" (Idem, Ibidem): que continuam oferecendo, specialmente neste nonagésimo aniversário da "Ata de incineração", informações importantes sobre a história do romance.

\section{Paulo Rigger: um brasileiro sui generis}

Entretanto, após seis anos a interpretação do romance veiculada pela "nota" e fundamentada na ideia, várias vezes repetida, de que Paulo Rigger é Jorge Amado, será desmentida pelo próprio escritor. O qual afirma, pelo contrário, que no romance:

${ }^{7}$ Nossos os grifos. 
[...] Há pois, ao mesmo tempo, uma atitude emprestada: os muito jovens tomam emprestada de um guru, para empregar um termo de hoje, de um homem que era cético, pertencia a outra época, e eu, que no livro quero tomar posição pela minha geração - que, neste ponto, é muito sincero e reflete muito bem as reações de um garoto desta idade. Assim, o Paulo Rigger de $O$ País do Carnaval é, de todos os heróis dos meus romances, aquele em que eu menos me projeto, o que me é mais estranho. É uma exceção, porque creio que em todos os meus outros livros meus personagens, meus heróis sempre têm algo a ver comigo.(RAILLARD, 1990, p. 47)

Portanto, sublinhada toda sua gratidão a Stegagno Picchio, Amado, em termos pacatos, mas nem por isso menos firmes, desmente de vez, para começar, uma questão crucial, e mais em geral para quantos ainda em 1990 achavam que o escritor fosse o "eteronimo", ou o alter ego de Paulo Rigger.

Mas, desmentindo a ideia fundamental da "nota", quer dizer, definindo seu personagem Paulo Rigger "uma exceção", Amado não desmentia que aquele brasileiro sui generis estava conotado, com as suas interpretações da realidade brasileira, por uma específica negatividade. Assim, as afirmações de Amado abriam em 1990 a novos possíveis cenários interpretativos, oferecendo informações que, combinadas com outras testemunhas (no caso em questão as de Panzini), permitiriam reavaliar os diferentes personagens e seus papéis no romance. Inclusive o do "comunista" José Lopes, que seria o único personagem a repudiar apertis verbis Paulo Rigger - com a afirmação "Por isso eu fugio de você" (AMADO, 1970, p. 114) - no último encontro antes do retorno do fazendeiro na Europa. Aquele José Lopes "comunista” no qual é verosímil que os inquisidores varguistas tenham facilmente reconhecido, a posteriori, o próprio Jorge Amado.

Hipotizamos que, em 1930, o escritor soubesse da existência seja das duas alcunhas inglesas antigamente usadas contra a Itália, seja da orgulhosa tomada de posição do lexicógrafo italiano Pan- 
zini, e tanto mais incisiva por constar até num dicionário. Agora, consideremos pelo contrário a possibilidade de que Amado não soubesse da reação de Panzini àquelas alcunhas contra o seu país. Mesmo assim, resta o fato que, como já em um maduro intelectual qual Panzini, uma justificada indignação poderia ter levado um adolescente escritor a reagir contra quem tomasse a liberdade de definir seu país o Paiz do Carnaval.

No aguardo de novos estudos numa perspectiva pluridisciplinar e transnacional - nos quais a Itália poderia exercer um papel decisivo como demonstram as atestações de Panzini - vale a pena observar que profunda é a diferença entre as linhas paratextuais adotadas por Stegagno Picchio e por Raillard para as duas primeiras traduções do romance amadiano. De fato, o "Advertissement" de Raillard, se por um lado evoca conceitos afirmados primeiro por Stegagno Picchio e depois por Amado, por outro lado implicitamente convida o leitor francês, pelas muitas facetas de Le Pays du Carnaval, a interrogar diretamente Jorge Amado na entrevista publicada no mesmo ano.

\section{Referências}

AMADO, Jorge. O Paiz do Carnaval. Rio de Janeiro: Schmidt, 1931.

. O País do Carnaval. Cacau. Suor. São Paulo: Martins Editora, 1970.

. Il Paese del Carnevale. Traduzione dal portoghese di Elena Grechi. Con una nota di Luciana Stegagno Picchio. Milano: Garzanti Editore, 1984.

Gallimard, 1990.

Le Pays du Carnaval. Traduit du portugais par Alice Raillard. Paris: 
BAGNO, Sandra. Lessicografia e identità brasiliana: dov'è "A nossa Vendéia"? Da Alcácer-Quibir a Vendéia: voci del "tempo di lunga durata" della "civiltà nazionale" brasiliana. Padova: CLEUP, 2006.

. Revolução de 30 e carnaval: la carnavalização ante litteram di Jorge Amado. In: Rivista di Studi Portoghesi e Brasiliani XV-2013, Pisa-Roma: Fabrizio Serra Editore, MMXIV. p. 17-26.

ESTADO da BAHIA, 17/12/1937. Autor. Ata de incineração. Estado da Bahia. Bahia. 17/12/1937 pg.

FRAGA, Myriam (Org.). Catálogo do acervo de documentos Vol. I Jorge AmadoProdução ativa. Salvador: Fundação Casa de Jorge Amado, 2009. Disponível em: < http://www.jorgeamado.org.br/?page_id=172 >. Acesso em: 02 fev. 2017.

GENETTE, Gérard. Paratextos Editoriais. Tradução de Álvaro Faleiros. Cotia: Ateliê Editorial, 2009.

PANZINI, Alfredo. Dizionario Moderno. Milano: Hoepli, 1905.

. Dizionario Moderno. Nona Edizione com un proemio di A. Schiaffini e un'appendice di B. Migliorini. Milano: Hoepli, 1950.

RAILlARD, Alice. Conversando com Jorge Amado. Tradução de Annie Dymetman. Rio de Janeiro: Record, 1990.

Recebido em: 03/10/2016

Aceito em: 29/12/2016 Publicado em maio de 2017 